This item was submitted to Loughborough's Research Repository by the author.

Items in Figshare are protected by copyright, with all rights reserved, unless otherwise indicated.

\title{
Fabricating core-shell WC@C/Pt structures and its enhanced performance
} for methanol electrooxidation

PLEASE CITE THE PUBLISHED VERSION

https://doi.org/10.1063/1674-0068/30/cjcp1703026

PUBLISHER

(C) Chinese Physical Society

VERSION

VoR (Version of Record)

LICENCE

CC BY-NC-ND 4.0

\section{REPOSITORY RECORD}

Chen, Zhao-Yang, Long-Fa Duan, You-Qun Chu, Jiang-Feng Sheng, Wen-Feng Lin, and Chun-An Ma. 2018. "Fabricating Core-shell Wc@c/pt Structures and Its Enhanced Performance for Methanol Electrooxidation". figshare. https://hdl.handle.net/2134/28465. 
ARTICLE

Fabricating Core-Shell WC@C/Pt Structures and its Enhanced Performance for Methanol Electrooxidation

\author{
Zhao-yang Chen ${ }^{a *}$, Long-fa Duan ${ }^{a}$, You-qun Chu ${ }^{a *}$, Jiang-feng Sheng ${ }^{a}$, Wen-feng Lin ${ }^{b}$, \\ Chun-an $\mathrm{Ma}^{\mathrm{a}}$ \\ a. State Key Laboratory Breeding Base for Green Chemistry Synthesis Technology, College of Chemical \\ Engineering, Zhejiang University of Technology, Hangzhou 310032, China \\ b. Department of Chemical Engineering, Loughborough University, Loughborough, Leicestershire, LE11 \\ 3TU, UK
}

(Dated: Received on March 3, 2017; Accepted on June 10, 2017)

\begin{abstract}
The spray-dried spheres within a $\mathrm{W} / \mathrm{Pt}$ multi-separation can be used to prepare discrete core-shell WC@C/Pt catalysts through a typical carburization production mechanism at $800{ }^{\circ} \mathrm{C}$. In contrast with previous studies of the $\mathrm{WC} / \mathrm{Pt}$ synthesis, the reaction observed here proceeds through an indirect annealing mechanism at $600{ }^{\circ} \mathrm{C}$ wherein species diffuse, thereby resulting in core-shell structure, and Pt nanoparticles were successfully dispersed in size/shape and randomly scattered across the in situ produced $\mathrm{C}$ spheres. Through direct carburization or at higher initial hydrochloroplatinic acid concentrations, however, complete reaction with core-shell spheres was not observed. Indirect carburization reduces the strain felt by the bonds featuring the larger WC particles and allows the motion of carbon around $\mathrm{WC}$ and $\mathrm{Pt}$ nanoparticles to be reserved, influencing the electrocatalytic performance and stability toward methanol oxidation.
\end{abstract}

Key words: Self-disperse, Core-shell structure, Carbon-resist, Tungsten carbide, Methanol oxidation

\section{INTRODUCTION}

Pt-based catalysts demonstrate superior activity and stability for methanol electro oxidation in DMFC (Direct methanol fuel cells), and typical bimetallic catalysts include Pt-Ru, Pt-Au, and Pt-Pd alloys [1-4]. Researches, in recent years, mostly focused on the costeffective and $\mathrm{CO}$ anti-poisoning improvement of Pt metals to accelerate the commercialization of DMFC [58]. Pt nano-metalling, crystal plane control, and support effects are the main strategies to enhance the unit activity. The same synergistic effect strategy has also been extended to several other support effects systems. It is critical, therefore, to prepare high-efficiency precious metal-free supports (WC $[9,10]$, MoC [11], and $\left.\mathrm{TiO}_{2}[12,13]\right)$, which is an effective way to reduce the $\mathrm{Pt}$ particle diameter and also increase the anti-poisoning ability. Tungsten carbide (WC) displays potential applications for Pt-like behavior [14], COtolerance [15], and highly electrical conductivity [16] as support part in anode-catalysts for methanol oxidation reaction (MOR) $[17,18]$. Special crystal structures WC materials (porous WC [19-21], WC microspheres [22], nanochains [23], nanorods and nanoplatelets [24]) have

*Authors to whom correspondence should be addressed. E-mail: chenzhy@zjut.edu.cn, chuyq@zjut.edu.cn been prepared to enhance the electro-catalytic properties and stability for methanol oxidation. However, porous WC always exhibits coarse particle and smaller surface area than active carbon for its higher molecular mass. It has been researched to synthesize nano scale WC with a controllable size for achieving higher surface area, such as WC nanotubes with the diameter ranging from $30 \mathrm{~nm}$ to $70 \mathrm{~nm}[25,26]$. WC nanoparticles with an average size of $20 \mathrm{~nm}$ in diameter [27]. Actually, the single WC particle is still difficult to meet the requirements for application in electrocatalysis.

The more active centers, therefore, must be effectively created by the nano WC-Pt contact of hybrid from construction of hierarchical pores rather than typical Pt doped WC particles. Furthermore, the coreshell hetero structures became an increasingly promising structure for the WC-Pt series catalysts, for it could effectively tailor the electronic structures which led to the dramatically enhanced catalytic ability and chemical stability [28].

Herein we reported a study in which the core-shell structure could be readily formed via a facile and costeffective method. More specifically, Pt and WC structures have been successfully in situ fabricated and welldefined on core-shell WC@C spheres. The as-prepared core-shell WC@C/Pt spheres manifest markedly enhanced electro catalytic performance and stability toward methanol oxidation. The reasons could be ascribed to the more active sites, the well mesoporous 
WC@C core-shell structures and synergistic effect between Pt catalyst and WC support.

\section{EXPERIMENTS}

\section{A. Synthesis of the micro-sized spherical composites precursor (MSCP)}

MSCP was prepared using spray drying (BCHI Spray Dryer B-290) treated an aqueous solution. A mixture of ammonium meta tungstate (AMT, $\left.\left(\mathrm{NH}_{4}\right)_{2} \mathrm{~W}_{4} \mathrm{O}_{13} \cdot x \mathrm{H}_{2} \mathrm{O}\right)$ and chloroplatinic acid $\left(\mathrm{H}_{2} \mathrm{PtCl}_{6} \cdot 6 \mathrm{H}_{2} \mathrm{O}, 6.4 \mathrm{wt} \% \mathrm{Pt}\right.$ loaded vs. WC) were added to deionized water at $5 \mathrm{wt} \%$. During spray drying process, the velocity of aqueous solution was $20 \mathrm{~mL} / \mathrm{min}$, the temperature of drying at the threshold and outlet was 200 and $100{ }^{\circ} \mathrm{C}$, respectively.

\section{B. Synthesis of the core-shell WC@C/Pt catalysts}

The as-made MSCP underwent the process of calciation in air at $600{ }^{\circ} \mathrm{C}$ for $2 \mathrm{~h}$, the obtained powder was then removed to a quartz tube, and was sent into tubal resistance furnace, which had been purified by $\mathrm{N}_{2}$ for $0.5 \mathrm{~h}$. Then this product underwent the gas-solid reaction under an atmosphere of $\mathrm{CO} / \mathrm{H}_{2}\left(125 / 250 \mathrm{~cm}^{3} / \mathrm{min}\right)$, the temperature was then increased to $800{ }^{\circ} \mathrm{C}$ and maintained for $4 \mathrm{~h}$, the resulting product was denoted as indirect-carb $\mathrm{WC} @ \mathrm{C} / \mathrm{Pt}$. To be comparable, the precursor was directly carbonized without the heat treatment process under otherwise identical conditions, and the resulting product was denoted as direct-carb WC@C/Pt, $\mathrm{H}_{2} \mathrm{PtCl}_{6}$-free direct-carb WC was synthesized in the $\mathrm{H}_{2} \mathrm{PtCl}_{6}$-free directly carburization with other conditions same as direct-carb WC@C/Pt.

\section{Characterization}

The crystalline structures, composition, and morphology were investigated by X-ray diffraction analyzer (XRD, Rigakv D/max-III), scanning electron microscopy (SEM, Hitachi S-4800), high-resolution TEM using a Tecnai G2 F30 S-Twin microscope (FEI, Netherlands) at a voltage of $200 \mathrm{kV}$ and a current of $103 \mathrm{~mA}$ coupled with energy dispersive X-ray spectrometer (EDX, Thermo NORAN VANSTAGE ESI). The thermogravimetric analysis (TGA) was performed on Pyris diamond thermoanalyzer. Particle-size distribution curve was performed on Malvern laser particle analyzer (MS2000). BET surface areas and pore size distributions were determined on a physical adsorption instrument (ASAP 2020, Micro-meritics Co., USA).

\section{Electrochemical measurements}

Electrochemical measurements were carried out using a CHI600C electrochemical station, and a standard three-electrode setup with a saturated calomel electrode (SCE) and Pt foil as the reference and counter electrodes, respectively. For working electrode fabrication, indirect-carb and direct-carb WC@C/Pt (5 mg, respectively) were dispersed in a mixture aqueous solution of ethanol $(1 \mathrm{~mL})$ and Nafion solution (5 wt\%, $125 \mu \mathrm{L})$ under ultrasonic treatment for $10 \mathrm{~min}$. Afterwards, $10 \mu \mathrm{L}$ of the catalyst ink (containing $0.044 \mathrm{mg}$ of catalyst) were loaded onto a glassy carbon electrode $(3 \mathrm{~mm}$ in diameter). Cyclic voltammetry $(\mathrm{CV})$ was measured in $\mathrm{N}_{2}$ saturated $0.5 \mathrm{~mol} / \mathrm{L} \mathrm{H}_{2} \mathrm{SO}_{4}$ and $0.5 \mathrm{~mol} / \mathrm{L} \mathrm{CH}_{3} \mathrm{OH}$ solution at a scan rate of $50 \mathrm{mV} / \mathrm{s}$. All the electrochemistry experiments were carried out at room temperature. The commercial Pt/C (20\% Pt on Vulcan XC-72R, Johnson Matthey Corp.) and Pt black were also tested for comparison.

\section{RESULTS AND DISCUSSION}

SEM images of the MSCP are shown in FIG. 1(a), hollow microsphere with thin wall $(200-300 \mathrm{~nm})$ were observed from the broken ones, the diameter of the microspheres was about $200 \mathrm{~nm}-5 \mu \mathrm{m}$. It also can be found that the surface of hollow spherical was relatively smooth and there were an amount of spheres adhering to the surface both internal and external.

To investigate the factors contributing to the formation of the microsphere structure, TG-DTA patterns of the original AMT and MSCP are shown in inset of FIG. 1(a). It can be speculated that the reaction of the original AMT (red line) in each stage along with the different temperature range is as follows:

(i) The mass of the AMT begins to decrease at the temperature from $150{ }^{\circ} \mathrm{C}$ to $230{ }^{\circ} \mathrm{C}$, and weight loss comes to $3.85 \%$ of original weight. It is quite clear that the mass losses derive from free water and part of the crystalline water in original AMT, the equation is given by:

$$
\begin{aligned}
& 3\left(\mathrm{NH}_{4}\right)_{2} \mathrm{O} \cdot 12 \mathrm{WO}_{3} \cdot 10 \mathrm{H}_{2} \mathrm{O} \rightarrow \\
& \quad 3\left(\mathrm{NH}_{4}\right)_{2} \mathrm{O} \cdot 12 \mathrm{WO}_{3} \cdot 3 \mathrm{H}_{2} \mathrm{O}+7 \mathrm{H}_{2} \mathrm{O}(\mathrm{g})
\end{aligned}
$$

(ii) In the second step, decomposition between 290 and $340{ }^{\circ} \mathrm{C}$ leads to $5.01 \%$ weight loss, the resulting products are mainly ammonia, gaseous water and tungstate. The thermal decomposition reaction formula can be written as:

$$
\begin{aligned}
3\left(\mathrm{NH}_{4}\right)_{2} \mathrm{O} \cdot 12 \mathrm{WO}_{3} \cdot 3 \mathrm{H}_{2} \mathrm{O} \rightarrow & \left(\mathrm{NH}_{4}\right)_{2} \mathrm{O} \cdot 12 \mathrm{WO}_{3}+ \\
& 4 \mathrm{NH}_{3}(\mathrm{~g})+5 \mathrm{H}_{2} \mathrm{O}(\mathrm{g})(2)
\end{aligned}
$$

(iii) The weight of sample reduces slightly in the final decomposition around $390-410{ }^{\circ} \mathrm{C}$, only results in $1.50 \%$ weight loss. This situation illustrates tungstate 

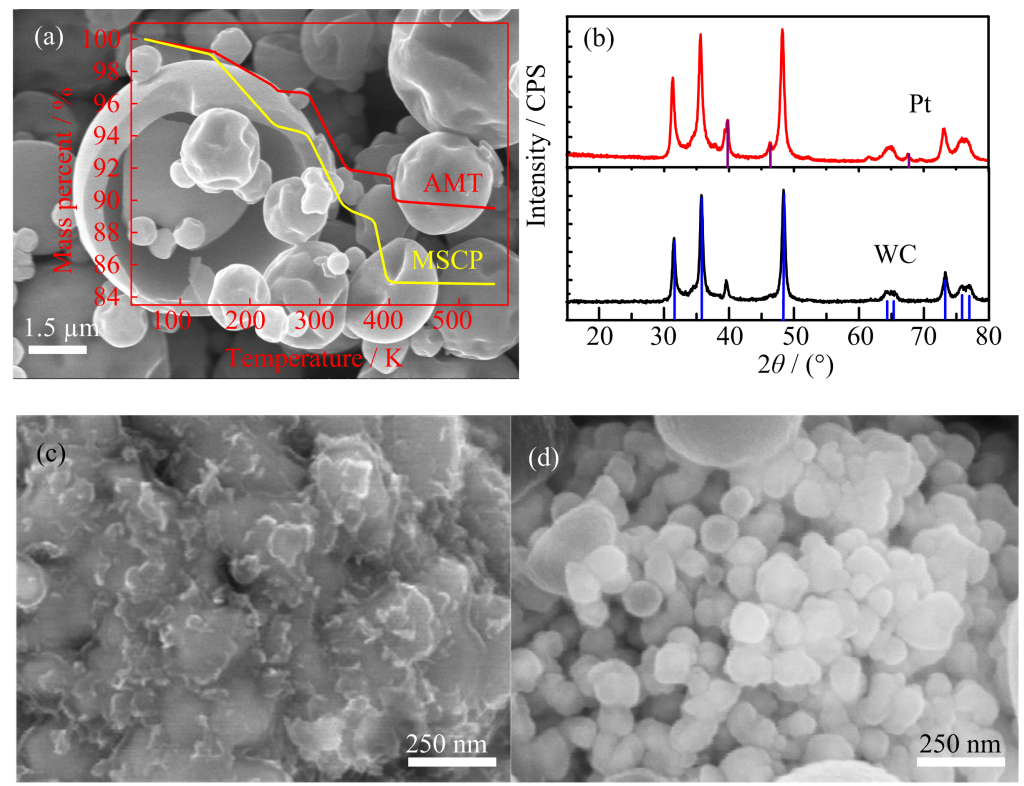

FIG. 1 (a) SEM images of the MSCP and TG curves (inset) of the original AMT and MSCP. (b) XRD patterns of direct-carb (black line) and indirect-carb (red line) WC@C/Pt composite. SEM images of (c) direct-carb WC@C/Pt and (d) indirect-carb WC@C/Pt composite.

has already decomposed into tungsten trioxide $\left(\mathrm{WO}_{3}\right)$, as shown in Eq.(3):

$$
\begin{aligned}
&\left(\mathrm{NH}_{4}\right)_{2} \mathrm{O} \cdot 12 \mathrm{WO}_{3}(\text { amorphous }) \rightarrow 12 \mathrm{WO}_{3}+2 \mathrm{NH}_{3}(\mathrm{~g})+ \\
& \mathrm{H}_{2} \mathrm{O}(\mathrm{g})
\end{aligned}
$$

The AMT decomposition was completed and became stable when the temperature was over $450{ }^{\circ} \mathrm{C}$, these results were consistent with the previous reports [29]. As seen in FIG. 1(a) (inset, yellow line), there are a lot of free water loss in the MSCP (weight loss take up $0.99 \%$ ) from room temperature to $150{ }^{\circ} \mathrm{C}$ compared with original AMT. The crystal water of AMT and $\mathrm{H}_{2} \mathrm{PtCl}_{6}$ are lost with the weight decreasing $4.55 \%$ in the temperature range of $150-255{ }^{\circ} \mathrm{C}$. After that, $\mathrm{AMT}$ and $\mathrm{H}_{2} \mathrm{PtCl}_{6}$ decomposed into tungstate and platinum tetrachloride $\left(\mathrm{PtCl}_{4}\right)$, respectively, and the weight decreased about $5.50 \%$ in the range of $285-335{ }^{\circ} \mathrm{C}$. Tungstate and $\mathrm{PtCl}_{4}$ eventually decomposed into $\mathrm{WO}_{3}$, chlorine $\left(\mathrm{Cl}_{2}\right)$ and platinum chloride $\left(\mathrm{PtCl}_{2}\right)$ from $375{ }^{\circ} \mathrm{C}$ to $400{ }^{\circ} \mathrm{C}$, respectively. In addition to the equation of AMT, the extra chemical reactions for MSCP could be formulated as follows:

$$
\begin{aligned}
& \mathrm{H}_{2} \mathrm{PtCl}_{6} \cdot 6 \mathrm{H}_{2} \mathrm{O} \rightarrow 6 \mathrm{H}_{2} \mathrm{O}+\mathrm{H}_{2} \mathrm{PtCl}_{6} \\
& \mathrm{H}_{2} \mathrm{PtCl}_{6} \rightarrow \mathrm{PtCl}_{4}+2 \mathrm{HCl} \\
& \mathrm{PtCl}_{4} \rightarrow \mathrm{PtCl}_{2}+\mathrm{Cl}_{2}
\end{aligned}
$$

This information showed that $\mathrm{Cl}^{-}$concentration became lower during the heating process, and excessive reunion can be resisted. Thus, the heat treatment at $600{ }^{\circ} \mathrm{C}$ was employed to promote the formation of mesoporous structure and particles [30]. The sample was prepared after annealing and carbonization process, and signed as indirect carb WC@C/Pt. By contrast, we also obtained the sample through direct carburation of the MSCP without $600{ }^{\circ} \mathrm{C}$ anneal process and signed as direct-carb WC@C/Pt. To analyze the phase structure, XRD patterns determinations were applied to characterize the obtained samples after the MSCP carburization. FIG. 1(b) shows XRD pattern of the as-synthesized WC@C/Pt, where main peaks at $2 \theta=31.52^{\circ}, 35.70^{\circ}$, and $48.25^{\circ}$ correspond to diffractions from (001), (100), and (101) planes of hexagonal WC (JCPDS No.51-0939). Moreover, XRD pattern displays diffraction peaks at $39.79^{\circ}$, $46.28^{\circ}$, and $67.53^{\circ}$ correspond to the crystal planes of Pt (111), (200), and (220), respectively. The XRD data confirmed the formation of Pt nanoparticles with face-centered-cubic (fcc), which was consistent with the JCPDS No.87-0646. Nevertheless, compared with direct-carb WC@C/Pt, the indirect-carb WC@C/Pt exhibited stronger $\mathrm{Pt}$ diffraction peaks, especially (111) direction, which was due to the indirect carburization process in favor of the $\mathrm{Pt}$ growth prefering (111) direction. For Pt crystal, the surface energies associated with the low-index crystallographic planes were in the order of $\gamma(111)<\gamma(100)<\gamma(110)$ [31]. Carbon component, which was produced in the indirect carburization process, provided better macroscopic melting condition as the support of the Pt nano particles. During the high temperature treatment, the (111) plane of $\mathrm{Pt}$ in the indirect carburization sample was in dominant growth. The Pt particles in the direct carburization sample were covered by the $\mathrm{WC}$ and the lower surface energy plane was not in dominant growth. 

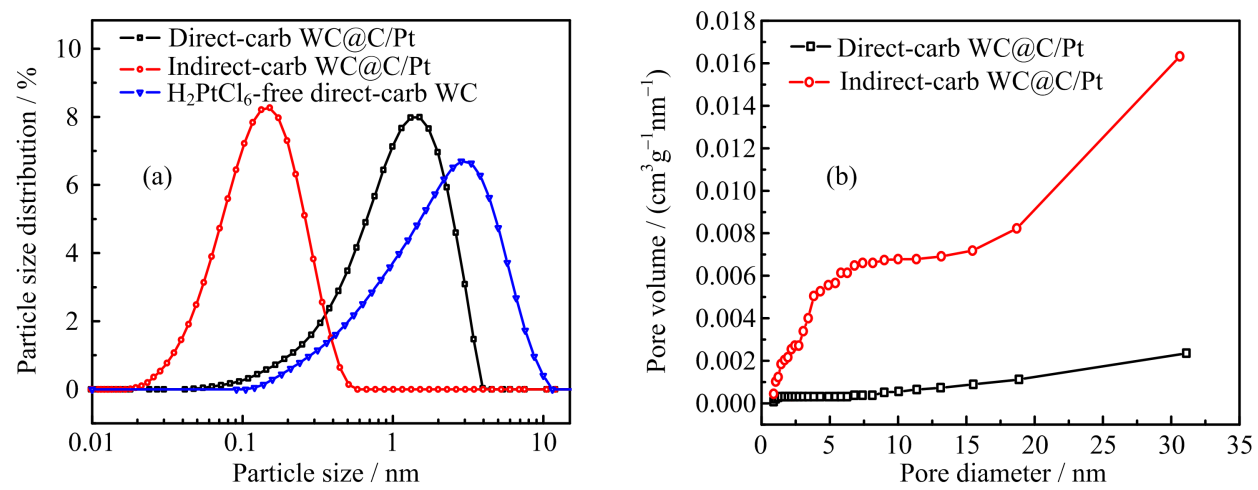

FIG. 2 (a) The particle size distributions of $\mathrm{H}_{2} \mathrm{PtCl}_{6}$-free direct-carb WC and direct/indirect-carb WC@C/Pt. (b) Pore size distributions for direct/indirect-WC@C/Pt sample.

The microstructures and morphologies for WC@C/Pt were determined by SEM. From FIG. 1(c), the $\mathrm{WC} @ \mathrm{C} / \mathrm{Pt}$ obtained by direct carbonization was severely agglomerated with coarse particles, on the contrary, the indirect-carb WC@C/Pt (FIG. 1(d)) displayed a remarkably spherical structure with diameters ranging between 50 and $120 \mathrm{~nm}$.

The particle size distributions of direct-carb WC and direct/indirect-carb WC@C/Pt are given in FIG. 2(a). Compared to $\mathrm{H}_{2} \mathrm{PtCl}_{6}$-free direct-carb WC sample, the particle size of direct-carb WC@C/Pt decreased slightly due to that the carburization with participation of $\mathrm{Cl}^{-}$ led the particle to agglomerate, which finally promoted WC particles size to increase. However, particle size distributions of indirect-carb WC@C/Pt exhibited much smaller than direct-carb $\mathrm{WC} @ \mathrm{C} / \mathrm{Pt}$, resulted from the indirect-carburization processes which made the larger WC particles break and the secondary particles reduce greatly in size. The results indicated that the indirectcarburization processes promoted the ball to uniformly disperse and particles size to decrease during high temperature and carburization processes with $\mathrm{Cl}^{-}$participating. This phenomenon was much different from typical double heating treatments which inevitably became more highly branched and eventually entangled into large WC and Pt agglomerates. The discrepancies appeared to be related to the effect of chloride $\left(\mathrm{Cl}^{-}\right)$ions from $\mathrm{H}_{2} \mathrm{PtCl}_{6}$ or $\mathrm{PtCl}_{2}$. In indirect carbonizing process, the crystal water, $\mathrm{NH}_{3}, \mathrm{HCl}, \mathrm{Cl}_{2}$ were removed and the mesoporous skeleton structure of MCSP was formed, it was beneficial to $\mathrm{Cl}^{-}$ions (from $\mathrm{PtCl}_{2}$ ) removal and impeded the secondary reunion of $\mathrm{WC}$ and $\mathrm{Pt}$ nanoparticles for WC@C/Pt. We also added $\mathrm{H}_{2} \mathrm{PtCl}_{6}$ in higher concentration (10 wt $\%$ and $15 \mathrm{wt} \% \mathrm{Pt}$ loaded on $\mathrm{WC}$ ), the MCSP particles were much larger than the original one, which was caused by the $\mathrm{Cl}^{-}$concentration and solution viscosity increase. And the spray-dried particles would not be well preserved.

Pore size distributions of different samples are given in FIG. 2(b). The results indicate that indirectcarb WC@C/Pt exhibits a higher specific surface

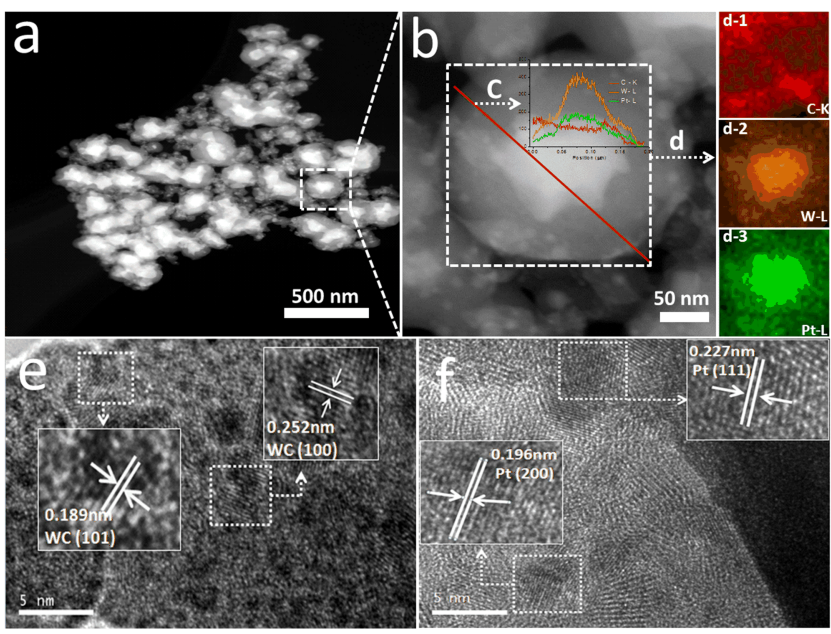

FIG. 3 (a, b) STEM images, (c) EDX line-scan analysis and (d1, d2, d3) elemental mapping, (e, f) HRTEM images of the indirect-carb WC@C/Pt composite.

$\left(11.687 \mathrm{~m}^{2} / \mathrm{g}\right)$ which is 17.3 times of direct-carb $\mathrm{WC} @ \mathrm{C} / \mathrm{Pt}\left(0.675 \mathrm{~m}^{2} / \mathrm{g}\right)$. Pore size distribution shows the indirect-carb $\mathrm{WC} @ \mathrm{C} / \mathrm{Pt}$ has better mesoporous structures. It is clear that the higher surface area was resulted mostly from the mesopores even when there were micropores present. These mesopores formed partially because the carbons were in situ produced from the CO decomposition during the carbonization.

FIG. 3 (a)-(f) shows the typical STEM and highresolution TEM (HRTEM) images of indirect-carb $\mathrm{WC} @ \mathrm{C} / \mathrm{Pt}$ as well as their elemental distribution. Clearly, the material displays spheres with core-shell structure from FIG. 3(a). The core-shell structure was further confirmed by EDX line-scan analysis along the selected line across the particle (FIG. 3(b), red line). As shown in FIG. 3(c), it showed distinctly the WC-core and C-shell structure for WC@C/Pt.

Moreover, in order to demonstrate the Pt nanoparticles can be well-dispersed on the WC support, elemental mapping had been performed and it proved $\mathrm{C}, \mathrm{W}$ and 

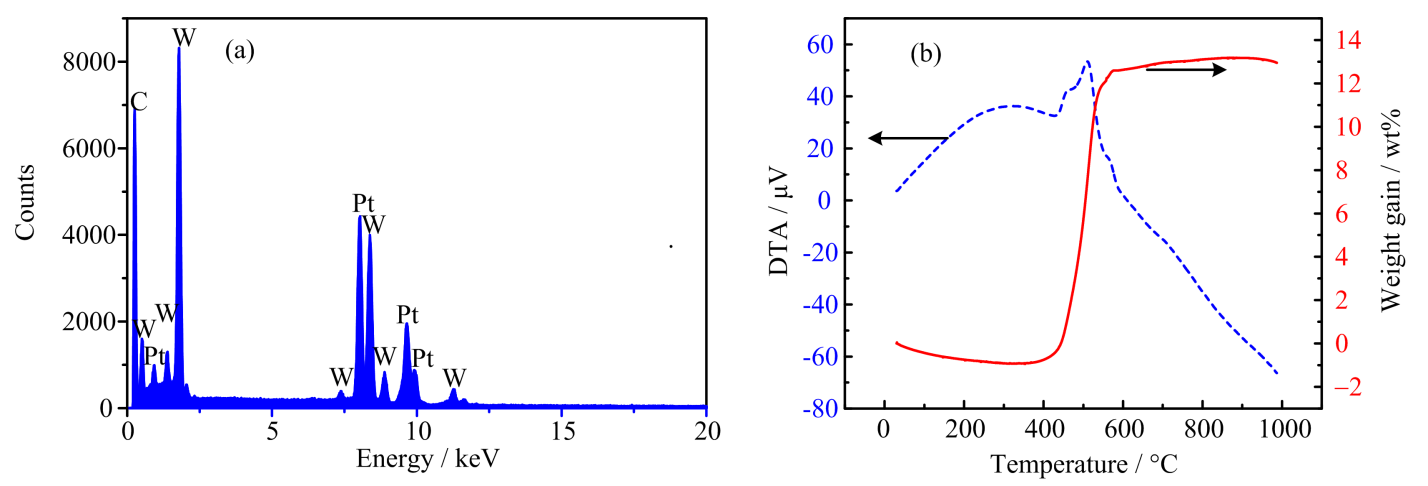

FIG. 4 (a) EDX spectrum and (b) TG-DTA curves of indirect-carb WC@C/Pt.
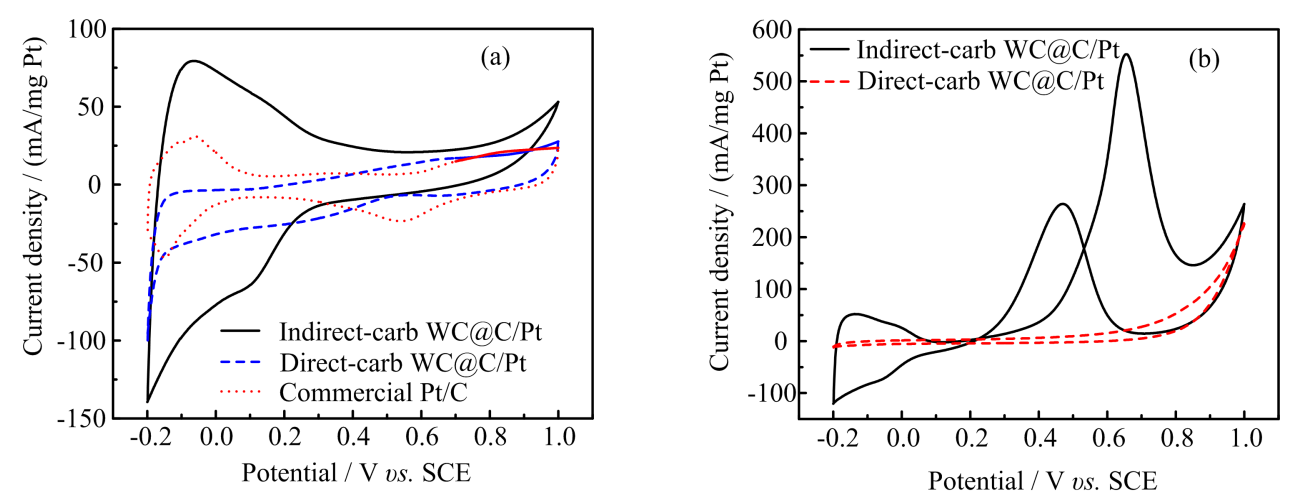

FIG. 5 (a) Cyclic voltammograms of indirect-carb WC@C/Pt, direct-carb WC@C/Pt and commercial Pt/C catalysts in $\mathrm{N}_{2}$-protecting $0.5 \mathrm{~mol} / \mathrm{L} \mathrm{H}_{2} \mathrm{SO}_{4}$ electrolyte, (b) cyclic voltammograms curves on different electrodes in $0.5 \mathrm{~mol} / \mathrm{L}$ $\mathrm{H}_{2} \mathrm{SO}_{4}+0.5 \mathrm{~mol} / \mathrm{L} \mathrm{CH}_{3} \mathrm{OH}$ electrolyte at a scan rate of $50 \mathrm{mV} / \mathrm{s}$.

Pt were uniformly distributed and overlapped in the spheres (FIG. 3(d1, d2, d3)). As shown in HRTEM image (FIG. 3(e, f)), the crystalline lattices of WC (101) and (100), Pt (111), and (200) facets can be clearly observed, which is consistent with the results of XRD analysis. It shows that WC with mesoporous carbon shells on which $\mathrm{WC}$ and $\mathrm{Pt}$ particles uniformly dispersed have been prepared. Pt and WC thus successfully were separated without more impregnation or high-temperature hydrogen-reduction processes.

The quantitative analysis of the elements from the $\mathrm{STEM}$ region of indirect-carb $\mathrm{WC} @ \mathrm{C} / \mathrm{Pt}$ by $\mathrm{EDX}$ is shown in FIG. 4(a), confirming the existence of W, C and $\mathrm{Pt}$, which is also proven by the mapping images (FIG. 3(d)) and XRD curves (FIG. 1(b)). However, the mass ratio of the $\mathrm{WC}$ to $\mathrm{Pt}$ will not be confirmed by the EDX. TG analysis under air was used to determine the percent WC present in indirect-carb $\mathrm{WC} @ \mathrm{C} / \mathrm{Pt}$ sample. Assuming all carbon from $\mathrm{WC}$ and $\mathrm{C}$ was removed as $\mathrm{CO}_{2}$ (with no other impurities presented), the mass of $\mathrm{WC}$ was calculated as follows:

$$
\begin{aligned}
m_{i} & =m_{\mathrm{WC}}+m_{\mathrm{Pt}}+m_{\mathrm{C}} \\
m_{i} & =m_{\mathrm{WO}_{3}} \frac{M_{\mathrm{WC}}}{M_{\mathrm{WO}_{3}}}+m_{\mathrm{Pt}}+m_{c}
\end{aligned}
$$

where $m_{i}$ is initial mass, $m_{\mathrm{WC}}$ is mass of pure WC, $m_{\mathrm{Pt}}$ is mass of Pt, $m_{\mathrm{C}}$ is mass of carbon, $m_{\mathrm{WO}_{3}}$ is mass of pure $\mathrm{WO}_{3}, M_{\mathrm{WC}}$ is molecular mass of $\mathrm{WC}, M_{\mathrm{WO}_{3}}$ is molecular mass of $\mathrm{WO}_{3}$.

TG analyses of the WC samples under air show large mass gains of about 12.8 wt\% (FIG. 4(b), solid curve). $\mathrm{WC}$ and $\mathrm{Pt}$ were $69.6 \mathrm{wt} \%$ and $4.2 \mathrm{wt} \%$ (calculated by the $\mathrm{Pt}$ adding ratio vs. $\mathrm{W}$ ) for indirect-carb $\mathrm{WC} @ \mathrm{C} / \mathrm{Pt}$ sample, respectively. The oxidation point in air was also tested by the DTA result (FIG. 4(b), broken cure). The sample would be oxidized and become stable during $420-580{ }^{\circ} \mathrm{C}$.

The electrochemical measurements were used to characterize the surface composition of the prepared $\mathrm{WC} @ \mathrm{C} / \mathrm{Pt}$ catalyst. FIG. 5(a) shows the $\mathrm{CVs}$ of indirect-carb $\mathrm{WC} @ \mathrm{C} / \mathrm{Pt}$, direct-carb $\mathrm{WC} @ \mathrm{C} / \mathrm{Pt}$, and commercial $\mathrm{Pt} / \mathrm{C}$ electrodes in a $\mathrm{N}_{2}$-saturated $0.5 \mathrm{~mol} / \mathrm{L} \mathrm{H}_{2} \mathrm{SO}_{4}$ solution. The comparison of the hydrogen adsorption/desorption behavior on different electrodes shows that the indirect-carb WC@C/Pt hybrid possesses a higher catalytic activity in the electro oxidation of hydrogen. The electrochemical surface area (ESA) of the Pt catalyst on the electrode surface has been estimated using the charge densities associated with adsorption/desorption of $\mathrm{H}$ de- 

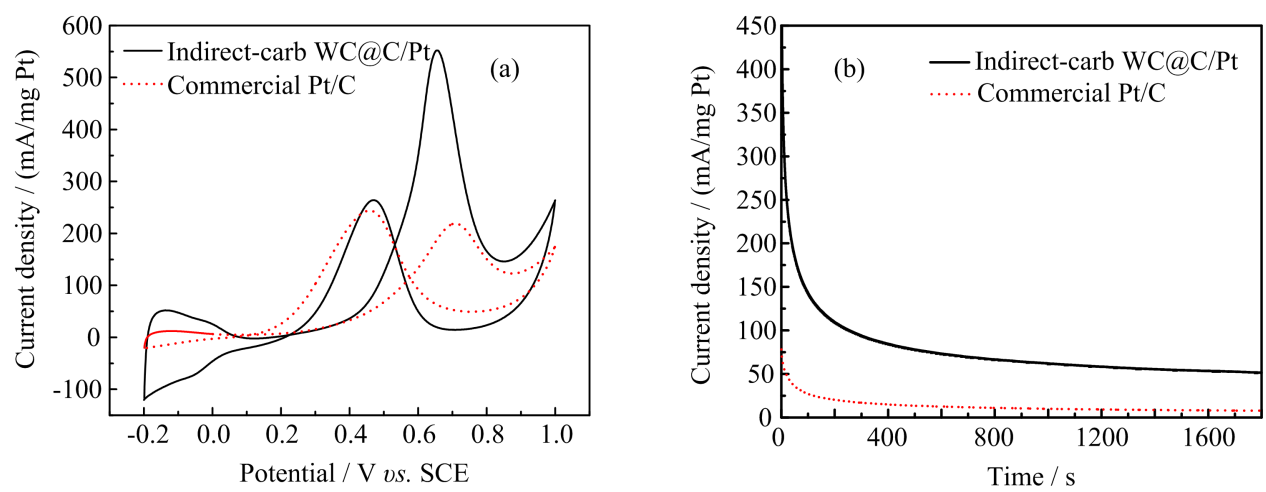

FIG. 6 (a) Cyclic voltammograms of indirect-carb WC@C/Pt and commercial Pt/C catalysts in $\mathrm{N}_{2}$-protecting 0.5 mol/L $\mathrm{H}_{2} \mathrm{SO}_{4}+0.5 \mathrm{~mol} / \mathrm{L} \mathrm{CH}_{3} \mathrm{OH}$ electrolyte at a scan rate of $50 \mathrm{mV} / \mathrm{s}$. (b) Chronoamperometry curves on different electrodes in $0.5 \mathrm{~mol} / \mathrm{L} \mathrm{H}_{2} \mathrm{SO}_{4}+0.5 \mathrm{~mol} / \mathrm{L} \mathrm{CH}_{3} \mathrm{OH}$ electrolyte.

rived from corresponding $\mathrm{CV}$ curves according to the reported literature [32]. The ESA of the indirectcarb WC@C/Pt $\left(177.76 \mathrm{~m}^{2} / \mathrm{g}\right)$ is higher than commercial $\mathrm{Pt} / \mathrm{C}\left(44.39 \mathrm{~m}^{2} / \mathrm{g}\right)$. However, the direct-carb $\mathrm{WC} @ \mathrm{C} / \mathrm{Pt}$ shows no catalytic activity in the electro oxidation of hydrogen. The larger ESA of the indirect-WC@C/Pt catalyst can provide more active sites, which is significant for enhanced electro activities of the indirect-WC@C/Pt catalyst.

To assess their electro catalytic property in the methanol oxidations, the cyclic voltammograms curves on different electrodes were collected in $0.5 \mathrm{~mol} / \mathrm{L}$ $\mathrm{CH}_{3} \mathrm{OH}$ containing $0.5 \mathrm{~mol} / \mathrm{L} \mathrm{H}_{2} \mathrm{SO}_{4}$ solutions, as shown in FIG. 5(b). The electro catalytic activities of WC@C/Pt catalysts towards methanol oxidations were found to be highly dependent on the microstructure in the composite. As presented in FIG. 5(b), the indirectcarb WC@C/Pt catalysts displayed considerable activity for methanol oxidation, while there was no activity to the direct-carb WC@C/Pt catalysts. It could be ascribed to the latter lack of the electrochemical active sites due to the bigger particle size and aggregation of $\mathrm{Pt}$ on the surface of WC.

Additionally, the indirect-carb WC@C/Pt catalysts electro catalytic activity $(552.16 \mathrm{~mA} / \mathrm{mg} \mathrm{Pt})$ towards methanol oxidation was significantly higher than that of $\mathrm{Pt} / \mathrm{C}(218.93 \mathrm{~mA} / \mathrm{mg} \mathrm{Pt})$, as could be seen from FIG. 6(a). This was because Pt nanoparticles were uniformly dispersed in size/shape and randomly scattered across the in situ produced $\mathrm{C}$ by indirect carburization. In addition, in methanol electro oxidation, the tungsten carbide acts as adsorption site of hydroxyl ion, for which the intermediate species on $\mathrm{Pt}$ surface can be effectively removed on $\mathrm{Pt}$ surface during the methanol oxidation reaction. The larger ESA of the indirect-WC@C/Pt catalyst could provide more active sites, which was significant for enhanced electro activities of the indirect-WC@C/Pt catalyst. Thus, we can expect that the highly improved electro catalytic properties of the indirect-WC@ $\mathrm{C} / \mathrm{Pt}$ may result from the above discussion.

To further compare the long-term electro catalytic stabilities of catalyst materials, the current densitytime curves are recorded in FIG. 6(b). The indirectcarb WC@C/Pt and Pt/C catalysts present gradually decay of current density $(55.49 \mathrm{~mA} / \mathrm{mg} \mathrm{Pt} v s$. Pt/C $7.82 \mathrm{~mA} / \mathrm{mg} \mathrm{Pt}$ ) with the extension of time due to gradual accumulation of intermediate products $(\mathrm{CO})$ which poisons the catalysts. Besides, FIG. 6(b) also shows that the indirect-carb $\mathrm{WC} @ \mathrm{C} / \mathrm{Pt}$ catalyst possesses the best electrocatalytic stability of two catalysts due to the synergy between $\mathrm{Pt}$ and $\mathrm{WC}$ as discussed above.

\section{CONCLUSION}

In summary, we have developed a simple effective method for the synthesis of discrete core-shell $\mathrm{WC} @ \mathrm{C} / \mathrm{Pt}$ catalysts through a typical carburization production mechanism at $800{ }^{\circ} \mathrm{C}$. The spheres $\mathrm{WC} @ \mathrm{C} / \mathrm{Pt}$ catalysts exhibited higher catalytic activity for electrochemical methanol oxidation reaction (552.16 mA/mg Pt vs. Pt/C $218.93 \mathrm{~mA} / \mathrm{mg} \mathrm{Pt}$ ), and exceed 7 times higher in stability than a commercial $\mathrm{Pt} / \mathrm{C}$ catalyst. By contrast, the as-prepared samples without the process of calcining showed no activity towards methanol oxidation due to lack of active sites. The thermal treatment promoted the formation of mesoporous structure and particles. It benefited the Pt nanoparticles to be dispersed in size/shape and randomly scattered across the carbon spheres in the carbonizing process, which was believed to be the vital factor for the high quality catalysts. The current methods can be extended to synthesize other noble metals for wider ranges of electro catalysis and may find applications in a myriad of electrochemical processes.

\section{ACKNOWLEDGMENTS}

This work is supported by the International Science \& Technology Cooperation Program of China 
(No.2010DFB63680), the Natural Science Foundation of Zhejiang Province (LQ15B030004) and Loughborough University and the EPSRC (EP/I013229/1).

[1] M. Winter and R. J. Brodd, Chem. Rev. 104, 42 (2004).

[2] X. Yang, Q. D. Yang, J. Xu, and C. S. Lee, J. Mater. Chem. 22, 8057 (2012).

[3] K. Mikkelsen, B. Cassidy, N. Hofstetter, L. Bergquist, A. Taylor, and D. A. Rider, Chem. Mater. 26, 6928 (2014).

[4] N. Zhang, S. J. Guo, X. Zhu, J. Guo, and X. Q. Huang, Chem. Mater. 28, 4447 (2016).

[5] H. Zhang, M. S. Jin, and Y. N. Xia, Chem. Soc. Rev. 41, 8035 (2012).

[6] J. R. C. Salgado, F. Alcaide, G. Alvarez, L. Calvillo, and M. J. Lazaro, J. Power Sources 195, 4022 (2010).

[7] W. J. Zhou, Z. H. Zhou, S. Q. Song, W. Z. Li, G. Q. Sun, P. Tsiakaras, and Q. Xin, Appl. Catal. 46, 273 (2003).

[8] A. Chen and P. H. Hindle, Chem. Rev. 110, 3767 (2010).

[9] S. Bukola, B. Merzougui, A. Akinpelu, and M. Zeama, Electrochimica Acta 190, 1113 (2016).

[10] G. Singla, K. Singh, and O. P. Pandey, Int. J. Hydrogen Energy 40, 5628 (2015).

[11] Z. X. Yan, J. M. Xie, and P. K. Shen, J. Power Sources 286, 239 (2015).

[12] K. Woan, G. Pyrgiotakis, and W. Sigmund, Adv. Mater. 21, 2233 (2009).

[13] S. Y. Zhang, N. P. Philipp, J. W. Joshua, S. Dai, M. J. Xu, G. W. George, C. Matteo, A. P. Frank, and X. Q. Pan, Nano Lett. 16, 4528 (2016).

[14] R. B. Levy and M. Boudart, Science 181, 547 (1973).
[15] J. G. Chen, Chem. Rev. 96, 1477 (1996).

[16] H. Chhina, S. Campbell, and O. Kesler, J. Power Sources 179, 50 (2007).

[17] R. H. Wang, C. G. Tian, L. Wang, B. L. Wang, H. B. Zhang, and H. G. Fu, Chem. Commun. 3104 (2009).

[18] G. S. Raman, J. H. Dong, and S. L. Jae, Electrochem. Commun. 9, 2576 (2007).

[19] J. S. Moon, Y. W. Lee, S. B. Han, and K. W. Park, Int. J. Hydrogen Energy 39, 7798 (2014).

[20] R. Ganesan and J. S. Lee, Angew. Chem. Int. Ed. 44, 6557 (2005).

[21] C. A. Ma, Z. Y. Chen, W. F. Lin, F. M. Zhao, and M. Q. Shi, Micropor. Mesopor. Mater 149, 76 (2012).

[22] Y. Wang, S. Song, V. Maragou, P. K. Shen, and P. Tsiakaras, Appl. Catal. B 89, 223 (2009).

[23] Y. Wang, S. Q. Song, P. K. Shen, C. X. Guo, and C. M. Li, J. Mater. Chem. 19, 6149 (2009).

[24] S. Shanmugam, D. S. Jacob, and A. Gedanken, J. Phys. Chem. B 109, 19056 (2005).

[25] V. G. Pol, S. V. Pol, and A. Gedanken, Adv. Mater. 23, 1179 (2011).

[26] V. G. Pol, S. V. Pol, and A. Gedanken, Adv. Mater. 18, 2023 (2006).

[27] F. P. Hu and P. K. Shen, J. Power Sources 173, 877 (2007).

[28] Z. Y. Chen, C. A. Ma, Y. Q. Chu, J. M. Jin, X. Lin, C. Hardacre, and W. F. Lin, Chem. Commun. 49, 11677 (2013).

[29] G. J. French and F. R. Sale, J. Mater. Sci. 16, 3427 (1981).

[30] Z. Y. Chen, M. Q. Shi, C. A. Ma, Y. Q. Chu, and A. J. Zhu, Powder Technol. 235, 467 (2013).

[31] J. Chen, B. Lim, E. P. Lee, and Y. Xia, Nano Today 4, $81(2009)$.

[32] Y. J. Li, W. Gao, L. J. Ci, C. M. Wang, and P. M. Ajayan, Carbon 48, 1124 (2010). 